\title{
ОБОСНОВАНИЕ РЕГЛАМЕНТА ПРОХОДКИ ПАРАЛЛЕЛЬНЫХ ВЗАИМОВЛИЯЮЩИХ ВЫРАБОТОК В НАПРЯЖЕННЫХ ТРЕЩИНОВАТЫХ СКАЛЬНЫХ МАССИВАХ
}

\author{
Харисов Тимур Фаритович1, \\ timur-ne@mail.ru
}

\author{
Балек Александр Евгеньевич1, \\ balek@igduran.ru
}

\section{Озорнин Иван Леонидович 1 , ivan.ozornin@igduran.ru}

1 Институт горного дела УрО РАН,
Россия, 620219, г. Екатеринбург, ул. Мамина-Сибиряка, 58.

\begin{abstract}
Актуальность исследования обусловлена необходимостью учета взаимного влияния выработок, сооружаемых в напряженных трещиноватых массивах скальных пород, с целью сохранения устойчивости сближенных выработок в процессе их строительства и эксплуатащии.

Целью исследования является оценка размеров зоны деформирования, образующейся вокруг одиночной горизонтальной выработки в процессе ее строительства, с последующим обоснованием типов и параметров крепи, обеспечивающей их устойчивость.

На основании результатов экспериментально-аналитических исследований процессов деформирования системы «крепьмассив», которые были получены и накоплены на протяжении 50 лет в процессе строительства выработок в массиве хромитовых месторождений Донского ГОКа, выполнена оценка напряженно-деформированного состояния породного массива в масштабах шахтного поля и обоснована геомеханическая модель массива, находящегося в условиях запредельного деформирования, характеризующаяся постепенным хрупким разрушением пород и последующими взаимными перемещениями структурных блоков на глубинах свыше 500-600 м.

Результаты. Расчетным методом определены радиусы зон деформирования массива, формирующихся в различных условиях вокруг капитальных выработок для всего диапазона проектных глубин исследуемого месторождения. Выявлен интервал оптимальных значений отпора и несущей способности крепи, обеспечивающих уменьшение радиусов зон деформирования вокруг горизонтальных протяженных и большеобъемных выработок дробильно-перепускных комплексов. Разработан технологический регламент проходки и крепления такого типа выработок, в котором учтены процессы запредельного деформирования породного массива, происходящие вокруг каждой из выработок. Выполнено обоснование типов (спецпрофиль СВП

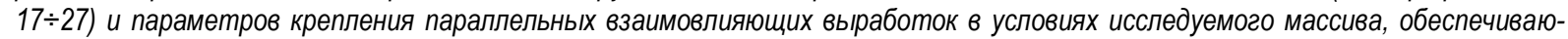
щих требуемый отпор и устойчивость сближенных выработок, как в процессе проходки, так и при последующей эксплуатации. Апробация и практическая реализация полученных технологических решений в настоящее время осуществляется 8 процессе строительства околоствольных дворов новой очереди шахты ДНК Донского горно-обогатительного комбината.
\end{abstract}

\section{Ключевые слова:}

Массив горных пород, натурные исследования, напряженно-дефрормированное состояние, структурное строение, иерархическая блочность.

\section{Введение}

Строительство сближенных параллельных выработок околоствольных дворов шахт нередко сопровождается нарушениями крепи, вызванными взаимным влиянием зон деформирования приконтурного массива, формирующихся вокруг выработок в процессе их проходки. В устойчивых массивах I, II и III категорий, представленных прочными слаботрещиноватыми породами, данные зоны развиваются в соответствии с закономерностями деформирования упругой однородной среды. При этом радиус зоны влияния каждой выработки распространяется на 1-1,5 ее ширины [1-9]. Исследования влияния зоны деформирования одиночной выработки на соседние в условиях угольного массива показали, что она составляет около 2,0-2,5 ее ширины [10].

Однако деформации и нарушения крепи, произошедшие при строительстве горизонтальных и вертикальных выработок шахты «Десятилетие независимости Казахстана» (ДНК) Донского горно-обогатительного комбината (Дон ГОК, г. Хромтау, Казахстан) показа- ли отсутствие корреляции установленных ранее закономерностей с процессами деформирования, протекающими в скальном сильнотрещиноватом массиве IV-V категории устойчивости.

Повышенные размеры зоны деформирования вокруг одиночной выработки неоднократно фиксировались при проведении инструментальных наблюдений в процессе проходки. Прослеживался рост смещений деформационных реперов, установленных в приконтурных скважинах грузовой ветви гор. -215 м (глубина 660 м) скипового ствола шахты «Молодежная», при удалении забоя на расстояние до 80 м; на контуре бетонной крепи ствола «Вспомогательный» на глубине свыше 500 м при удалении забоя до 8 м; на контуре штрека висячего бока гор. - 135 м (глубина 580 м) шахты «Молодежная» при удалении забоя на расстояние до 5 м; на контуре породной стенки ствола «Клетевой» на глубинах 818-838 м при удалении забоя на расстояние до 20 м; на контуре спинок чугунных тюбингов ствола «Клетевой» на глубинах 886-954 м при удалении забоя на расстояние до 69 м [11]. 


\section{Объект и методы исследования}

С целью оценки размеров зоны деформирования, образующейся вокруг одиночной горизонтальной выработки в процессе ее строительства с последующим обоснованием типов и параметров крепи, обеспечивающей устойчивость сближенных выработок новой очереди, выполнено исследование напряженнодеформированного состояния массива хромитовых месторождений, основная часть которых в настоящее время разрабатывается шахтой ДНК на глубинах свыше 500-600 м.

Исследуемый массив сложен в основном серпентинизироваными дунитами со следующими физикомеханическими свойствами в образцах: предел прочности на одноосное сжатие $\sigma_{\text {сж }}=-45 \ldots-90$ МПа, на одноосное растяжение $\sigma_{\text {раст }}=5 \ldots 9$ МПа, статический модуль упругости $E=35 \ldots 40$ ГПа, статический коэффициент Пуассона $\mu=0,25 \ldots 0,30$. Разбитость многочисленными хаотичными трещинами и разноориентированными тектоническими нарушениями на разномасштабные структурные блоки, связи между которыми изначально довольно слабы, а при увлажнении, когда тальковидный милонитовый или серпофитовый заполнитель трещин становится мыльным на ощупь, падают практически до нуля, обуславливают чрезвычайно низкую (IV-V категория) устойчивость приконтурного массива выработок околоствольных дворов шахты.

Выявленное по результатам натурных исследований $[12,13]$ напряженно-деформированное состояние (НДС) породного массива в масштабах шахтного поля подразделяется на два основных участка, которые совпадают с очередностями отработки шахты. Вертикальные напряжения на обоих участках изменяются в соответствии с приращением $\gamma H$, а главные горизонтальные напряжения $\sigma_{\max }$ и $\sigma_{\min }$ определяются следующими эмпирическими зависимостями:

- на участке 1-й очереди: $\sigma_{\max }=\lambda \gamma H+14$ МПа, $\sigma_{\min }=\lambda \gamma H+(7 \ldots 10)$ МПа, при азимуте оси $\sigma_{\max }-$ $50 \ldots 60^{\circ}$

- на участке 2-й очереди: $\sigma_{\max }=\sigma_{\min }=\gamma H$, где $\gamma=0,026 \mathrm{MH} / \mathrm{M}^{3}$ - объемный вес породного массива; $H$ - рассматриваемая глубина, м; $\lambda=0,43$ - коэффициент бокового давления при коэффициенте Пуассона $\mu=0,3$.

\section{Обоснование геомеханической модели}

Многолетняя практика ведения горных работ на шахтах ДОН ГОКа показала, что на глубинах, превышающих 500-600 м, деформационные процессы, протекающие в массиве серпентинизированных пород, не соответствуют геомеханической модели деформирования сплошной упругой изотропной среды. Наиболее наглядным примером является факт продолжающегося роста деформаций приконтурного породного массива (конвергенция) по мере удалении забоя на расстояние, значительно превышающее значения 1-1,5 ширины проходимой выработки. Кроме того, фиксация смещений деформационных реперов, установленных в приконтурных скважинах, также свидетельствует о наличии деформаций массива на расстояниях, на которых они должны отсутствовать согласно моделям однородной упругой среды [14].

Также стоит отметить и неприменимость для данных условий реологических моделей формирования НДС массива, которые предусматривают учет вязкости и ползучести деформируемой среды, на что указывали следующие факты:

1. Отсутствие постепенного роста смещений приконтурного массива горных выработок и нагрузок на крепь капитальных выработок за последние 40 лет подземной разработки на шахтах ДОН ГОКа противоречит расчетными значениям реологических моделей. Натурными исследованиями ИГД УрО РАН зафиксировано постепенное уменьшение напряжений в крепи со временем $[15,16]$.

2. По результатам замеров напряжений в крепи шахтных стволов установлено, что на глубине более 500-600 м при неизменных геологических условиях и параметрах крепи происходит резкий (в 5-6 раз) рост напряжений в крепи, связанное с увеличением зоны сдерживающего влияния забоя до 3-4 диаметров выработки. Соответственно, в разы увеличивается окружающая зона неупругих деформаций, что негативно сказывается на устойчивости прилегающих выработок.

3. По данным оптического буроскопического зондирования пород вокруг стволов и горизонтальных выработок установлено, что увеличение зоны неупругих деформаций является следствием нарушения сплошности и последующего запредельного деформирования вмещающего массива, проявляющегося в сдвиговых и ротационных смещениях структурных породных блоков размерами от нескольких сантиметров до 1,5-2 м на величину $1-1,5$ см и более.

4. Результатами межблочных подвижек структурных блоков вмещающих пород в условиях запредельного деформирования являются неравномерные сосредоточенные нагрузки на крепь горных выработок, которые приводят к нарушению ее целостности, о чем свидетельствуют результаты исследований, полученные при разработке месторождений в сложных горно-геологических условиях $[15,16]$

Вышеизложенное свидетельствует, что в напряженном вмещающем массиве скальных пород при проходке выработок происходило запредельное деформирование, но не в соответствии с реологическими моделями сплошной изотропной среды, а в условиях модели упругого деформирования и постепенного хрупкого разрушения массива с последующими взаимными перемещениями (переупаковкой) его структурных блоков. Таким образом, был сделан вывод, что в исследуемом массиве на глубинах свыше 500-600 м в напряженных массивах серпентинизированных горных пород главными факторами, определяющими формирование НДС крепи выработок, служат не процессы деформирования, а процессы постепенного разрушения окружающего породного массива $[17,18]$. 
Вокруг проходимых выработок, вне зависимости от их формы, направленности и местоположения, формируются концентрические зоны с измененными геомеханическими характеристиками вмещающего массива, которые схематично можно подразделить на четыре типа (рис. 1):

1) зона ненарушенного массива (зона допредельного деформирования) с предельной прочностью на одноосное сжатие $[\sigma]$;

2) переходная зона запредельного деформирования с постепенным снижением прочности разрушаемого массива от $[\sigma]$ до $\left[\sigma_{0}\right]$;

3) зона остаточной прочности разрушаемого массива с пределом прочности на одноосное сжатие $\left[\sigma_{0}\right]=0,1[\sigma] ;$

4) зона руинного разрушения с практически нулевой прочностью массива на одноосное сжатие.

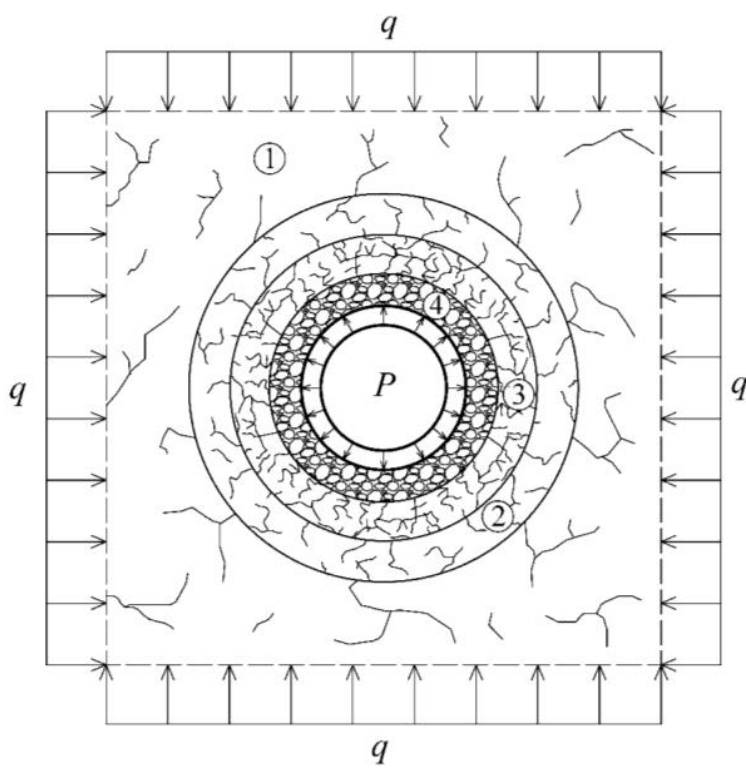

Pис. 1. Схема формирования нагрузок на крепь горной выработки в модели постепенного деформирования и разрушения массива: $q$ - внешние нагрузки; $P$ - отпор крепи

Fig. 1. Scheme of formation of loads on the support of the mine workings in the model of gradual deformation and fracture of massif: $q$ - external loads; $P$ - reinforce support

Формирование данных зон происходит не одномоментно, а в течение некоторого времени, что отражается в процессах постепенно затухающих смещений контура выработки, фиксируемых при инструментальных наблюдениях, в том числе при удалении забоя на расстояния, превышающие значения 1-1,5 ширины проходимой выработки.

Для условий шахт Дон ГОКа процессы разрушения вмещающего массива серпентинизированных скальных пород дополнительно активизируются при доступе воздуха и щелочной воды. Однако исследования ИГД УрО РАН показали, что основным фактором формирования нагрузок на крепь являются силовые условия, а не геохимические. Это подтверждено замерами радиальных смещений породного контура выработок и контура крепи, параметры которых в основном определялись размерами зон неупругого деформирования окружающих пород и реактивным отпором поддерживающей крепи, а не геохимическими процессами в закрепном пространстве [19].

\section{Обоснование параметров зон взаимного} влияния параллельных выработок

Более чем полувековой опыт экспериментальноаналитических исследований ИГД УрО РАН на шахтах Донского ГОКа $[15,20,21]$ показал, что при проходке параллельных выработок оценка безопасного расстояния между ними сводится к расчету области запредельного деформирования, формирующейся вокруг каждой из выработок. В расчетах окружающий породный массив лучше всего отображать моделью хрупкоразрушающейся среды. Для определения нагрузок на крепь такая модель дает определенный «запас прочности», по сравнению с моделью хрупко-пластического деформирования, поскольку в ней зона неупругих деформаций, формирующаяся вокруг выработки, совпадает с зоной разрушенных пород (рис. 1) [22]. При этом определяющее значение имеет не форма контура выработки, а площадь ее поперечного сечения, выраженная через эквивалентный радиус.

Согласно известным аналитическим решениям плоской геомеханической задачи [23] имеем:

- радиус $r$ зоны неупругого деформирования:

$$
r=R\left[\frac{\beta(2 q-[\sigma])+(\beta+2)\left[\sigma_{o}\right]}{(\beta+2)\left(\beta P+\left[\sigma_{o}\right]\right)}\right]^{1 / \beta} ;
$$

- радиальные смещения $U$ контура выработки:

$$
U=R\left[\frac{(1+\mu)(\beta q+[\sigma])}{E(\beta P+2)} r^{2}\right] ;
$$

внешняя максимальная (вертикальная) нагрузка $P_{\text {в на }}$ крепь от собственного веса налегающих разрушенных пород зоны неупругих деформаций:

$$
P_{\text {в }}=\chi(r-R),
$$

где $r$ - радиус (от центральной оси выработки) зоны разрушения и запредельного деформирования массива вмещающих горных пород (на рис. 1 это внешняя граница зон неупругих деформаций 2, 3, 4), м; $R=\sqrt{\frac{S}{\pi}}-$ эквивалентный радиус выработки, м; $S-$ площадь поперечного сечения выработки в проходке (вчерне), м²; $q$ - наибольшие главные нормальные напряжения (для условий объемного равнокомпонентного поля) окружающего породного массива выработки, МПа; $\beta=\frac{2 \sin \varphi}{1-\sin \varphi}-$ параметр линеаризации огибающей кругов Кулона-Мора; $\varphi$ - угол внутреннего трения; $\mu$ - коэффициент Пуассона; $[\sigma]$ - предел длительной прочности (на одноосное сжатие) вмещающего выработку породного массива вне зоны неупругих деформаций, МПа; $\left[\sigma_{0}\right]=0,1[\sigma]-$ предел остаточной прочности (на одноосное сжатие) нарушенного массива вмещающих пород в зоне неупругих деформаций, МПа; $P$ - реактивный отпор поддержи- 
вающей крепи, численно равный ее несущей способности, МПа; $\gamma$ - объемный вес породного массива в зоне неупругих деформаций.

Для условий проходки выработок руддворов 2 очереди шахты «ДНК» в качестве исходных геомеханических характеристик были приняты следующие значения:

- предел длительной прочности вмещающего породного массива на одноосное сжатие для диапазона IV-V категорий устойчивости: $[\sigma]=2-15$ МПа;

- предел остаточной прочности, соответственно: $\left[\sigma_{0}\right]=0,1[\sigma]=0,2-1,5 \mathrm{M \Pi a}$;

- главные нормальные напряжения $q$ вмещающего породного массива определяются зависимостью $\gamma H$;
- угол внутреннего трения вмещающего породного массива: $\varphi=30^{\circ}$ (соответственно, $\beta=2$ );

Подстановкой исходных параметров в формулу (1) рассчитаны радиусы $r$ зон неупругого деформирования вмещающегося породного массива, формирующихся в различных условиях вокруг капитальных выработок для всего диапазона проектных глубин 800-1428 м. Результаты расчетов, в графической форме представленные на рис. 2, показывают, что наиболее существенное влияние на размеры зоны неупругого деформирования и разрушения, формирующейся при проходке выработок руддворов 2 очереди, оказывает реактивный отпор поддерживающей крепи.

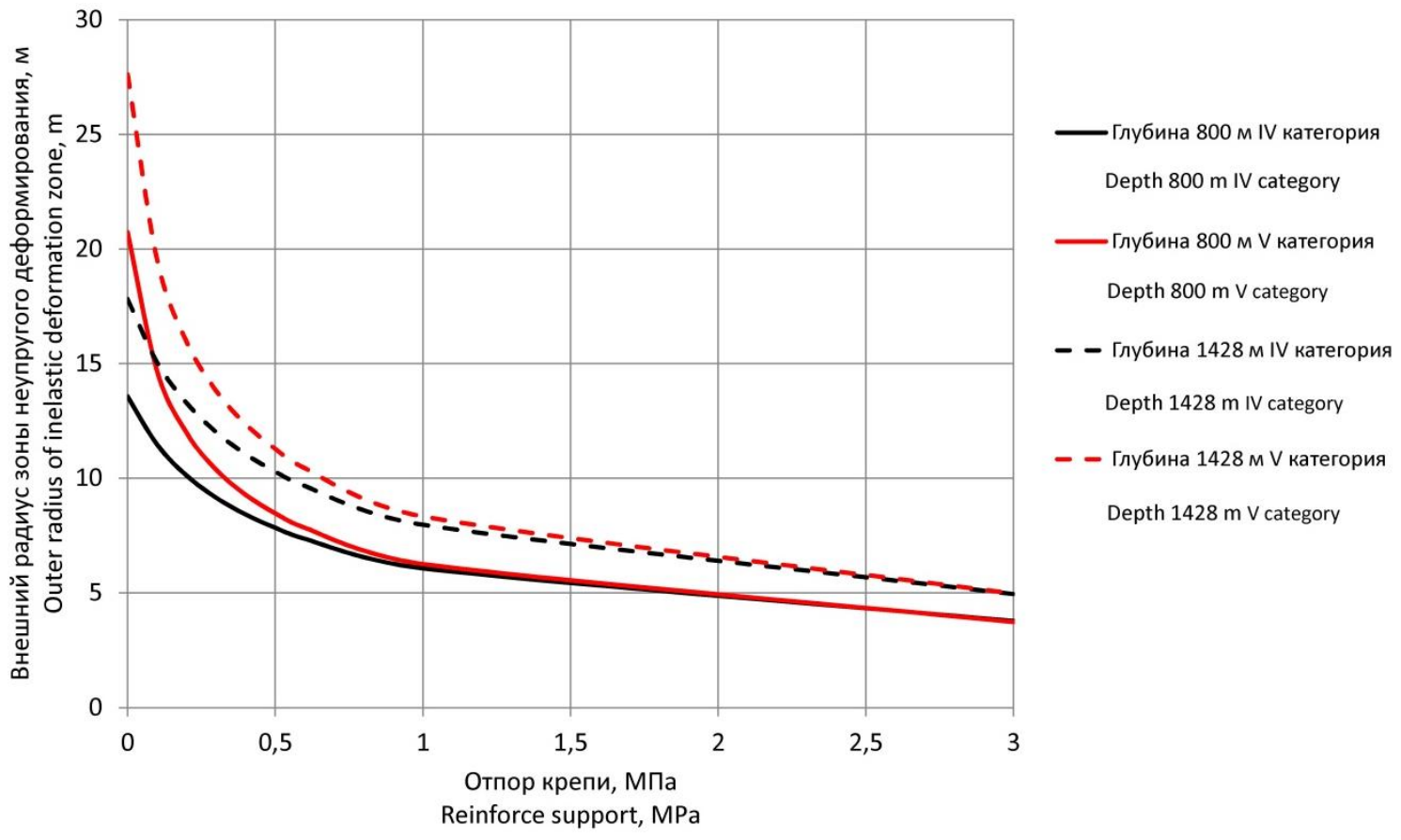

Pис. 2. Радиусы зоны неупругого деформирования массива в зависимости от величины отпора крепи при различных категориях устойчивости (на примере выработки эквивалентным радиусом $R=2 \mathrm{M}$ )

Fig. 2. Radii of the inelastic deformation zone of the massif depending on the size of the reinforce support at different categories of stability (for example, production of equivalent radius $R=2 \mathrm{~m}$ )

Расчеты оптимальных значений отпора и, соответственно, несущей способности, вида и параметров крепи, выполнены известным методом [24] графического решения плоской задачи совместного деформирования системы «крепь-массив» для наиболее неблагоприятной ситуации: при коэффициенте $\alpha^{*}$ сдерживающего влияния забоя равном единице. Определялись корни попарных комбинаций системы уравнений (2) и (3) для различных проектных параметров выработок 2 очереди шахты: глубин, в диапазоне от 800 до 1428 м и эквивалентных радиусов в диапазоне от 1 до 5 м для основных горно-капитальных выработок, проходимых в массивах IV и V категорий устойчивости.

В качестве примера на рис. 3 показано такое решение для выработок эквивалентным радиусом $R=2$ м, проходимых на различных глубинах в условиях IV категории устойчивости. Точки пересечения соот- ветствующих попарных комбинаций уравнений дают искомые значения оптимального отпора поддерживающей крепи $P$ в диапазоне от 0,21 до 0,27 МПа.

Аналогичные решения для выработок эквивалентным радиусом $R=5$ м в условиях IV категории устойчивости дают оптимальный отпор поддерживающей крепи $P$ в $0,41 \ldots 0,53$ МПа, а при V категории устойчивости для выработок шириной 4 и 10 м диапазоны оптимального отпора крепи составляют $P=0,24 \ldots 0,31$ и $P=0,45 \ldots 0,57 \mathrm{MПа,} \mathrm{соответственно.}$

\section{Обоснование регламента крепления}

Полученные результаты натурных инструментальных исследований показали, что при проходке подземных выработок во вмещающих скальных породных массивах 4-5 категорий устойчивости формируются концентрические зоны с измененными геомеханическими характеристиками. При этом главным критери- 
ем развития опасных геомеханических процессов, определяющих параметры геотехнической системы «крепь горной выработки - вмещающий породный массив», являются не процессы деформирования, а процессы разрушения, определяющие формирование в приконтурном массиве выработки концентрических зон с измененными геомеханическими характеристиками. Управление зонами неупругого деформирования и разрушения, формирующимися вокруг проходимых выработок, предлагается осуществлять за счет реактивного отпора поддерживающей крепи, численно равного ее несущей способности.

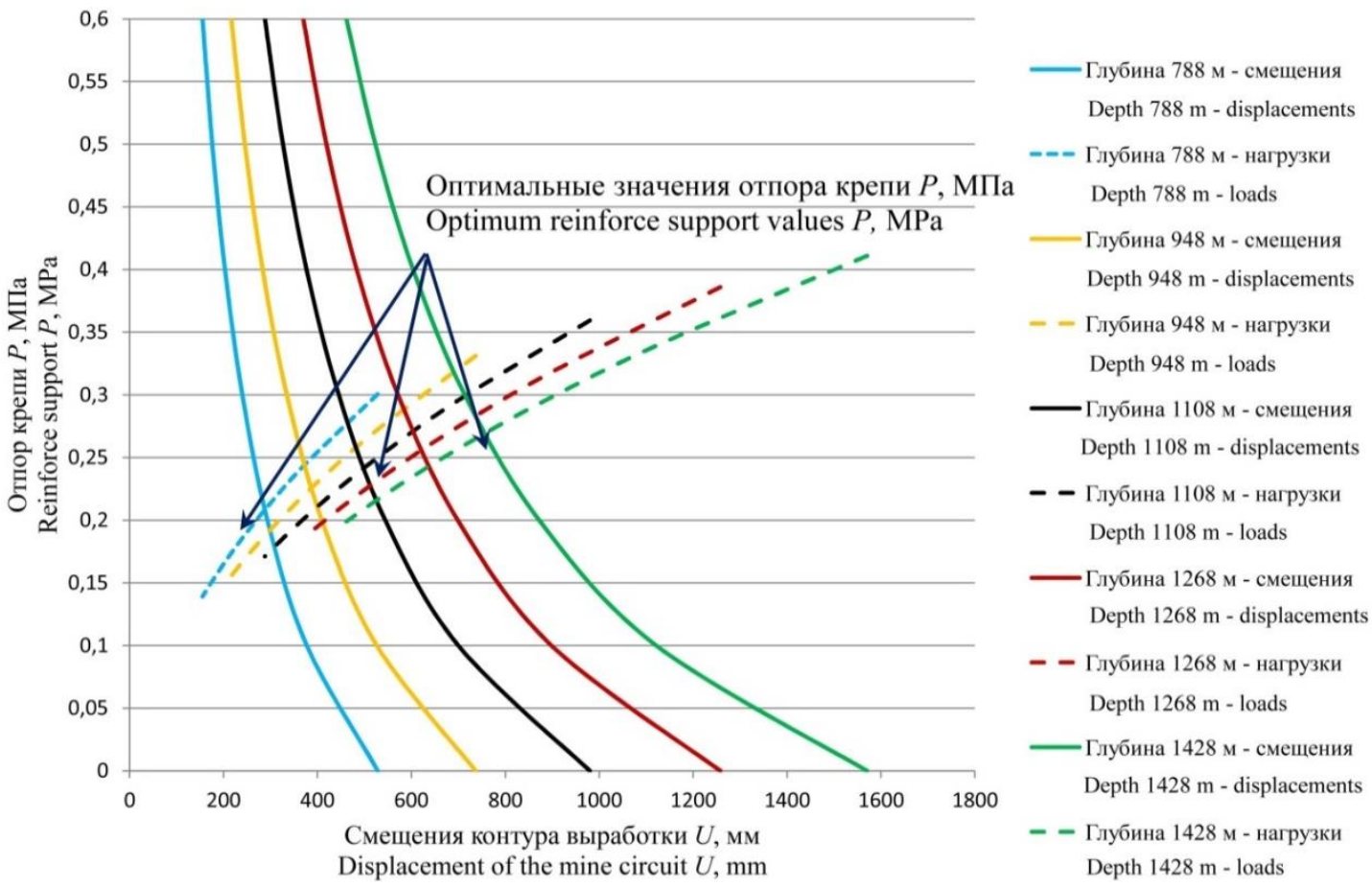

Pис. 3. Оптимальный отпор крепи выработки на различных глубинах (на примере выработки эквивалентным радиусом $R=2$ м в условиях IV категории устойчивости)

Fig. 3. Optimal support for different depths of the mine (with an example of an equivalent radius $R=2 \mathrm{~m}$ under stability category IV conditions)

Для рассматриваемых условий проходки выработок руддворов 2 очереди шахты «ДНК» оптимальный отпор поддерживающей крепи находится в пределах 0,1 ...0,3 МПа, а для большеобъемных выработок дробильно-перепускных комплексов и других камер 0,3...0,5 МПа (рис. 3). При этом вокруг выработок формируются зоны запредельного деформирования, внешние радиусы которых в $3 \ldots .7$ раз превышают поперечные размеры выработок вчерне.

Требуемый отпор крепи, при котором размеры зон запредельного деформирования в процессе проходки выработок оказываются оптимальными, обеспечивается за счет использовании в качестве временного крепления металлических арок из спецпрофиля СВП $17 . .27$ с шагом установки рам от 0,5 до 1,3 м (в зависимости размеров конкретной выработки и горногеологических и геомеханических условий) [25]. Выбор данного типа крепи обусловлен ее способностью сразу после возведения воспринимать на себя нагрузку со стороны массива, тем самым обеспечивая необходимый отпор и предотвращая развития зоны неупругого деформирования приконтурного массива.

Использование монолитной железобетонной крепей (рамы СВП + бетон) возможно только в качестве постоянной с отставанием от забоя на расстояние не менее 3-4 ширины выработки.
Виды и параметры временной и постоянной крепи сближенных выработок представлены в таблице. Однако предлагаемые параметры крепи можно варьировать, тем самым изменяя уровень отпора крепи и размеры зоны неупругого деформирования. Если сближенные выработки не попадают в зону взаимного влияния, то их проходка может производиться одновременно или с некоторым отставанием.

При отсутствии возможности исключить взаимное влияние выработок путем их разноски друг от друга на расстояние, превышающее радиус зоны разрушения окружающего массива, необходимо соблюдать очередность проходки и крепления выработок, после реализации основных деформационных процессов в приконтруном массиве. Первую одиночную выработку следует крепить только с применением временной крепи. Постоянная крепь не возводится. Затем производится проходка и крепление второй выработки, которая будет находиться в зоне неупругого деформирования, сформировавшейся в процессе проходки первоначальной выработки. После окончания строительства второй выработки производится визуальный осмотр первой выработки на предмет нарушений приконтурного массива и целостности временной крепи. При выявлении каких-либо нарушений выполняется еe ремонт, а затем возведение постоянной крепи. 
Таблица. Выбор типа крепи по категориям устойчивости пород

Table. Selection of the type of support by rock stability categories

\begin{tabular}{|c|c|c|c|}
\hline \multirow{2}{*}{$\begin{array}{c}\text { Категория } \\
\text { устойчивости } \\
\text { пород } \\
\text { Category of } \\
\text { rock stability } \\
\end{array}$} & \multirow{2}{*}{$\begin{array}{c}\text { Ширина } \\
\text { выработок } \\
\text { Width of workings }\end{array}$} & \multicolumn{2}{|r|}{$\begin{array}{l}\text { Требуемые виды крепления } \\
\text { Required support types }\end{array}$} \\
\hline & & $\begin{array}{c}\text { Постоянная } \\
\text { Permanent }\end{array}$ & $\begin{array}{l}\text { Временная } \\
\text { Temporary }\end{array}$ \\
\hline \multirow{3}{*}{$\begin{array}{l}\text { Неустойчивые } \\
\text { (IV) } \\
\text { Unstable (IV) }\end{array}$} & $\begin{array}{c}\text { до } 4 \mathrm{M} \\
\text { up to } 4 \mathrm{~m}\end{array}$ & $\begin{array}{l}\text { Монолитная железобетон- } \\
\text { ная крепь (рамы СВП + } \\
\text { бетонная крепь) } \\
\text { Monolithic ferroconcrete } \\
\text { support (SVP frames + con- } \\
\text { crete support) }\end{array}$ & $\begin{array}{l}\text { Комбинированная крепь: металлические рамы СВП } 17 \\
\text { (шаг установки не более } 0,8 \text { м) или СВП } 22 \text { (шаг установ- } \\
\text { ки не более } 1,0 \mathrm{~m} \text { ) с затяжкой } \\
\text { Combined support: metal frames SVP } 17 \text { (step of installation } \\
\text { not more than } 0,8 \text { m) or SVP } 22 \text { (step of installation not more } \\
\text { than } 1,0 \mathrm{~m} \text { ) with tightening }\end{array}$ \\
\hline & $4-6 \mathrm{~m} / \mathrm{m}$ & $\begin{array}{l}\text { Монолитная железобетон- } \\
\text { ная крепь (рамы СВП + } \\
\text { бетонная крепь) } \\
\text { Monolithic ferroconcrete } \\
\text { support (SVP frames + con- } \\
\text { crete support) }\end{array}$ & $\begin{array}{l}\text { Комбинированная крепь: металлические рамы СВП } 22 \\
\text { (шаг установки не более } 0,6 \text { м) или СВП } 27 \text { (шаг установ- } \\
\text { ки не более } 0,8 \text { м) или СВП } 33 \text { (шаг установки не более } \\
1,0 \text { м) с затяжкой } \\
\text { Combined support: metal frames SVP } 22 \text { (installation step no } \\
\text { more than } 0,6 \text { m) or SVP } 27 \text { (installation step no more than } \\
0,8 \text { m) or SVP } 33 \text { (installation step no more than } 1,0 \text { m) with } \\
\text { tightening }\end{array}$ \\
\hline & $\begin{array}{c}\text { более } 6 \mathrm{M} \\
\text { more than } 6 \mathrm{~m}\end{array}$ & $\begin{array}{l}\text { Монолитная железобетон- } \\
\text { ная крепь (рамы СВП + } \\
\text { бетонная крепь) + различ- } \\
\text { ные виды анкерной крепи } \\
\text { Monolithic ferroconcrete } \\
\text { support (SVP frames + con- } \\
\text { crete support) + various } \\
\text { types of anchor support }\end{array}$ & $\begin{array}{l}\text { Комбинированная крепь: металлические рамы СВП } 22 \\
\text { (шаг установки не более } 0,6 \text { м) или СВП } 27 \text { (шаг установ- } \\
\text { ки не более } 0,8 \text { м) или СВП } 33 \text { (шаг установки не более } \\
\text { 1,0м) с затяжкой + различные виды анкеров) } \\
\text { Combined support: metal frames SVP } 22 \text { (installation step no } \\
\text { more than } 0,6 \text { m) or SVP } 27 \text { (installation step no more than } \\
0,8 \text { m) or SVP } 33 \text { (installation step no more than } 1,0 \text { m) with } \\
\text { tightening + various types of anchors) }\end{array}$ \\
\hline $\begin{array}{l}\text { Весьма не- } \\
\text { устойчивые } \\
\text { (V) } \\
\text { Highly unstable } \\
\text { (V) }\end{array}$ & \multicolumn{3}{|c|}{$\begin{array}{l}\text { Требуется применение специальных методов проходки для перевода пород в более высокую IV категорию } \\
\text { устойчивости, т. е. применение податливых крепей в комбинации с опережающими и предохранительными } \\
\text { крепями (защитные экраны), либо необходимо инъектирование пород. } \\
\text { The use of special sinking methods is required to transfer the rocks to a higher IV stability category, i. e. the use of flexi- } \\
\text { ble supports in combination with advance and safety supports (protective screens), or the injection of rocks is required }\end{array}$} \\
\hline
\end{tabular}

При проходке сближенных выработок, одна из которых является большеобъемной с шириной более 6 м, первоочередной строящейся выработкой является большеобъемная, закрепленная постоянной железобетонной крепью. После чего выполняется проходка сближенной протяженной выработки, которая находится в зоне влияния первой выработки. При этом протяженная выработка крепится согласно таблице, чтобы зона деформирования, формирующаяся в процессе ее проходки, не оказала влияния на приконтурный массив большеобъемной выработки, тем самым предотвращая рост нагрузки на крепь и обеспечивая ее устойчивость.

\section{Заключение}

На основании экспериментально-аналитических исследований выполнено обоснование типов и парамет-

\section{СПИСОК ЛИТЕРАТУРЫ}

1. Саммаль А.С., Грибанов В.Б., Капунова Н.А. Оценка напряженного состояния массива пород в окрестности двух параллельных круговых выработок, сооружаемых в общей зоне укрепления // Известия Тульского государственного университета. Естественные науки. - 2013. - № 3. - С. 323-331.

2. Ларионов Р.И. Исследование формирования напряженнодеформированного состояния массива горных пород вокруг двух параллельно проведенных тоннелей // Записки Горного института. - 2007. - Т. 172. - С. 78-81.

3. Протосеня А.Г., Беляков Н.А., Куранов А.Д. Метод прогноза напряженного состояния комплекса тоннельных выработок сложной пространственной конфигурации с учетом взаимного влияния и последовательности строительства // Записки Горного института. - 2012. - Т. 199. - С. 17-24.

4. Deev P., Sammal A., Antziferov S. Evaluation of mine support stress state on base of convergence measurement data // International Multidisciplinary Scientific GeoConference ров крепления параллельных взаимовлияющих выработок, сооружаемых в напряженных массивах трещиноватых скальных горных пород, с целью обеспечения целостности крепи как в процессе проходки, так и при последующей эксплуатации выработок. Разработан технологический регламент проходки и крепления такого типа выработок, в котором учтены процессы запредельного деформирования породного массива, происходящие вокруг каждой из выработок. Апробация и практическая реализация полученных технологических решений осуществляется в процессе строительства околоствольных дворов новой очереди шахты ДНК Донского горно-обогатительного комбината.

Работа выполнена в ходе реализации государственного задания по теме № 0405-2019-0007.

Surveying Geology and Mining Ecology Management, SGEM 17, Science and Technologies in Geology, Exploration and Mining, Conference Proceedings. - Albena, Bulgaria, 2017. - P. 321-326.

5. Islavath S.R., Deb D., Kumar H. Development of a roof-to-floor convergence index for longwall face using combined finite element modelling and statistical approach // International Journal of Rock Mechanics and Mining Sciences. - 2020. - V. 127. - P. 204-221.

6. Elrawy W.R., Abdelhaffez G.S., Saleem H.A. Stability assessment of underground openings using different rock support systems // Rudarsko Geolosko Naftni Zbornik. - 2020. - V. 35 (1). - P. 49-64.

7. Measurement and analysis of the internal displacement and spatial effect due to tunnel excavation in hard rock / J. Wang, E. Li, L. Chen, Y. Han, C. Wang // Tunnelling and Underground Space Technology. - 2019. - V. 84. - P. 151-165.

8. Украинец В.Н. Совместное действие подвижных нормальной и скручивающей нагрузок на тоннель с круговой крепью // Известия Томского политехнического университета - 2007. T. 310. - № 1. - С. 58-61 
9. Исследование геодинамики массива в зоне сопряжения очистных и подготовительных выработок / В.И. Голик, В.И. Комащенко, Н.М. Качурин, Г.В. Стась // Известия Томского политехнического университета. Инжиниринг георесурсов. 2019. - Т. 330. - № 12. - С. 82-90.

10. Черданцев Н.В. Устойчивость анизотропного массива горных пород с системой двух спаренных выработок квадратного поперечного сечения // Вестник Научного центра по безопасности работ в угольной промышленности. - 2016. - № 3. - С. 6-13.

11. Innovative approaches to rock mass stability in mining high-grade quartz veins / A.D. Sashurin, A.A. Panzhin, T.F. Kharisov, D.Yu. Knyazev // Eurasian Mining. - 2016. - № 2. - P. 3-5.

12. Балек А.Е., Озорнин И.Л., Каюмова А.Н. Совместные замеры напряженного состояния и модуля упругости породного массива при проходке шахтных стволов // Горный информационно-аналитический бюллетень. - 2020. - № 4. - С 30-45.

13. Investigation on the evolution and control of surrounding rock fracture under different supporting conditions in deep roadway during excavation period / Z. Xie, N. Zhang, X. Feng, Q. Wei, M. Weng // International Journal of Rock Mechanics and Mining Sciences. - 2019. - V. 123. - № 104122.

14. Hedayat A., Weems J. The elasto-plastic response of deep tunnels with damaged zone and gravity effects // Rock Mechanics and Rock Engineering. - 2019. - V. 52 (12) - P. 5123-5135.

15. Балек А.Е. Обоснование условий снижения напряжений в крепи шахтных стволов // Горный информационноаналитический бюллетень. - 2011. - № S 11. - С. 51-65.

16. Effect of unloading velocity on surrounding rock deformation / G. Hou, J. Liang, M. Zhou, Y. Cui // Meitan Xuebao/Journal of the China Coal Society. - 2019. - V. 44 (4). - P. 1011-1019.

17. Investigation of deep mine shaft stability in alternating hard and soft rock strata using three-dimensional numerical modeling X. Sun, G. Li, C. Zhao, Y. Liu, C. Miao // Processes. - 2019. -
V. 7. - № 2. URL: https://www.mdpi.com/2227-9717/7/1/2 (дата обращения 01.09.2020).

18. Investigation of shaft stability and anisotropic deformation in a deep shaft in Idaho, United States / G. Walton, E. Kim, S. Sinha, G. Sturgis, D. Berberick // International Journal of Rock Mechanics and Mining Sciences. - 2018. - V. 105. - P. 160-171.

19. Deformation processes, textural evolution and weakening in retrograde serpentinites / C. Viti, C. Collettini, T. Tesei, M.S. Tarling, S.A.F. Smith // Minerals. - 2018. - V. 8 (6). № 241. URL: https://www.mdpi.com/2227-9717/7/1/2/htm (дата обращения 01.09.2020).

20. Результаты фундаментальных и прикладных научных исследований ИГД УрО РАН за 2012-2016 гг. / С.В. Корнилков, В.Л. Яковлев, А.В. Глебов, А.А. Панжин // Черная металлургия. Бюллетень научно-технической и экономической информации. - 2017. - № 1 (1405). - С. 98-103.

21. Сашурин А.Д. Формирование напряженно-деформированного состояния иерархически блочного массива горных пород // Проблемы недропользования. - 2015. - № 1 (4). - С. 38-44.

22. Соловьев В.А., Аптуков В.Н., Ваулина И.Б. Поддержание горных выработок в соляных породах // Горный информационно-аналитический бюллетень. - 2017. - № 2. - С. 344-356.

23. Балек А.Е. Особенности формирования напряжений в крепи вертикальных выработок в условиях запредельного напряженно-деформированного состояния скальных породных массивов // Горный информационно-аналитический бюллетень. 2014. - № 11. - C. 202-212.

24. Баклашов И.В., Картозия Б.А. Механика подземных сооружений и конструкции крепей. - М.: Изд-во «Недра», 1992. - 543 с.

25. Modelling of closed steel supports for underground and mining works / P. Janas, K. Janas, L. Koubova, M. Krejsa // Key Engineering Materials. - 2017. - V. 754. - C. 313-316.

Поступила 08.09.2020 2.

\section{Информация об авторах}

Харисов $\boldsymbol{T . \Phi . , ~ к а н д и д а т ~ т е х н и ч е с к и х ~ н а у к , ~ с т а р ш и и ̆ ~ н а у ч н ы и ̆ ~ с о т р у д н и к ~ л а б о р а т о р и и ~ г е о м е х а н и к и ~ п о д з е м н ы х ~}$ сооружений Института горного дела УрО РАН.

Балек A.E., доктор технических наук, ведущий научный сотрудник, Институт горного дела УрО РАН.

Озорнин И.Л., заведующий лабораторией геомеханики подземных сооружений Института горного дела УрО РАН. 
UDC 622.83

\title{
JUSTIFICATION OF REGULATIONS FOR DRIVING PARALLEL MUTUALLY INFLUENCING MINE WORKINGS IN STRESSED CRACKED ROCKY MASSIFS
}

\author{
Timur F. Kharisov' 1 , \\ timur-ne@mail.ru
}

\author{
Aleksandr E. Balek ${ }^{1}$, \\ balek@igduran.ru \\ Ivan L. Ozornin ${ }^{1}$, \\ ivan.ozornin@igduran.ru \\ 1 Institute of Mining of Ural Branch of RAS, \\ 58, Mamin-Sibiryak street, Ekaterinburg, 620075, Russia.
}

\begin{abstract}
The relevance of the research is caused by the necessity to account mutual influence of the mine workings constructed in the intense cracked massifs of rocks for preserving stability of the approached mine workings in the course of their building and operation.

The aim of study is to estimate the size of the deformation zone formed around a single horizontal mine workings during its construction with subsequent justification of the types and parameters of support, ensuring their stability. On the basis of the results of experimental and analytical studies of the "fastener-massif» system deformation, which were obtained and accumulated over 50 years in the course of construction of workings in the massif of chromite deposits of the Don Mining and Processing Complex, the assessment of stress-strain state of the rock massif on the scale of the mine field was made and the geomechanical model of the massif, which is characterized by gradual brittle destruction of rocks and subsequent crossovers, was justified.

Results. The radii of deformation zones of the massif formed in different conditions around capital excavations for the whole range of design depths of the investigated field have been determined by the calculated method. The interval of optimum values of the repulse and, accordingly, bearing capacity of the support, providing reduction of radiuses of deformation zones around the horizontal extended and large-volume excavations of crushing and bypass complexes, was determined. Technological regulations for driving and fastening of such workings are developed, which take into account the processes of rock deformation that occur around each workings. Justification of types

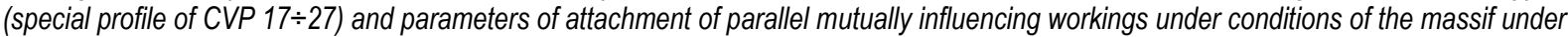
study, providing the required repulse and stability of the close workings, both in the process of driving and subsequent operation, was made. Testing and practical implementation of the obtained technological solutions is currently being carried out in the process of construction of near-barrelled yards of the new stage of the mine DNK of the Donsk Mining and Processing Integrated Works.
\end{abstract}

\section{Key words:}

Massif, in situ research, stress-strain state, structural structure, hierarchical block structure.

The research was carried out when implementing the State task on the topic no. 0405-2019-0007.

\section{REFERENCES}

1. Sammal A.S., Gribanov V.B., Kapunova N.A. Otsenka napryazhennogo sostoyaniya massiva porod $\mathrm{v}$ okrestnosti dvukh parallelnykh krugovykh vyrabotok, sooruzhaemykh $\mathrm{v}$ obshchey zone ukrepleniya [Stress state estimation of the rock massif in the vicinity of two parallel circular openings to be erected in the common area strengthen]. Izvestiya Tulskogo gosudarstvennogo universiteta. Estestvennye nauki, 2013, vol. 3, pp. 323-331.

2. Larionov R.I. Issledovanie formirovaniya napryazhennodeformirovannogo sostoyaniya massiva gornykh porod vokrug dvukh parallelno provedennykh tonneley [Investigation of the stress-strain state formation of a massif of rocks around two parallel tunnels]. Zapiski Gornogo instituta, 2007, vol. 172, pp. 78-81.

3. Protosenya A.G., Belyakov N.A., Kuranov A.D. Metod prognoza napryazhennogo sostoyaniya kompleksa tonnelnykh vyrabotok slozhnoy prostranstvennoy konfiguratsii s uchetom vzaimnogo vliyaniya i posledovatelnosti stroitelstva [The prediction technics of tunnel sets with complex three dimensional configuration stress state with allowance for relative influence and building sequence]. Zapiski Gornogo instituta, 2012, vol. 199, pp. 17-24.

4. Deev P., Sammal A., Antziferov S. Evaluation of mine support stress state on base of convergence measurement data. International Multidisciplinary Scientific GeoConference Surveying Geology and Mining Ecology Management, SGEM 17, Science and Technologies in Geology, Exploration and Mining, Conference Proceedings. Albena, Bulgaria, 2017. pp. 321-326.

5. Islavath S.R., Deb D., Kumar H. Development of a roof-to-floo convergence index for longwall face using combined finite element modelling and statistical approach. International Journal of Rock Mechanics and Mining Sciences, 2020, vol. 127, pp. 204-221.

6. Elrawy W.R., Abdelhaffez G.S., Saleem H.A. Stability assessment of underground openings using different rock support systems. Rudarsko Geolosko Naftni Zbornik, 2020, vol. 35 (1), pp. 49-64.

7. Wang J., Li E., Chen L., Han Y., Wang C. Measurement and analysis of the internal displacement and spatial effect due to tunnel excavation in hard rock. Tunnelling and Underground Space Technology, 2019, vol. 84, pp. 151-165.

8. Ukrainec V.N. Cojoint effect of mobile normal and torque loads on tunnel with circular support. Bulletin of the Tomsk Polytechnic University, 2007, vol. 310, no. 1, pp. 58-61. In Rus.

9. Golik V.I., Komashchenko V.I., Kachurin N.M., Stas G.V. Research of array geodynamics in the interface of cleaning and preparatory works. Bulletin of the Tomsk Polytechnic University. Geo assets Engineering, 2019, vol. 330, no. 12, pp. 82-90.

10. Cherdancev N.V. Stability of anisotropic rock massif with two adjacent square cross-section openings system. Industrial safety, 2016, no. 3, pp. 6-13. In Rus.

11. Sashurin A.D., Panzhin A.A., Kharisov T.F., Knyazev D.Yu. Innovative approaches to rock mass stability in mining high-grade quartz veins. Eurasian Mining, 2016, no. 2, pp. 3-5.

12. Balek A.E., Ozornin I.L., Kayumova A.N. Joint measurements of the stress state and modulus of elasticity of the rock mass during sinking shafts. Mining informational and analytical bulletin, 2020, no. 4 , pp. $30-45$.

13. Xie Z., Zhang N., Feng X., Wei Q., Weng M. Investigation on the evolution and control of surrounding rock fracture under different 
supporting conditions in deep roadway during excavation period International Journal of Rock Mechanics and Mining Sciences, 2019, vol. 123, no. 104122 .

14. Hedayat A., Weems J. The elasto-plastic response of deep tunnels with damaged zone and gravity effects. Rock Mechanics and Rock Engineering, 2019, vol. 52 (12), pp. 5123-5135.

15. Balek A.E. Substantiation of conditions to decreasing of the lining of mining shafts. Mining informational and analytical bulletin, 2011, no. S 11, pp. 51-65. In Rus.

16. Hou G., Liang J., Zhou M., Cui Y. Effect of unloading velocity on surrounding rock deformation. Meitan Xuebao/Journal of the China Coal Society, 2019, vol. 44 (4), pp. 1011-1019.

17. Sun X., Li G., Zhao C., Liu Y., Miao C. Investigation of deep mine shaft stability in alternating hard and soft rock strata using three-dimensional numerical modeling. Processes, 2019, vol. 7 , no. 2. Available at: https://www.mdpi.com/2227-9717/7/1/2 (accessed 1 September 2020).

18. Walton G., Kim E., Sinha S., Sturgis G., Berberick D. Investigation of shaft stability and anisotropic deformation in a deep shaft in Idaho, United States. International Journal of Rock Mechanics and Mining Sciences, 2018, vol. 105, pp. 160-171.

19. Viti C., Collettini C., Tesei T., Tarling M.S., Smith S.A.F. Deformation processes, textural evolution and weakening in retrograde serpentinites. Minerals, 2018, vol. 8 (6), no. 241. Available at https://www.mdpi.com/2227-9717/7/1/2/htm (accessed 1 September 2020).

\section{Information about the authors}

Timur F. Kharisov, Cand. Sc., senior researcher, Institute of Mining of Ural Branch of RAS.

Aleksandr E. Balek, Dr. Sc., leading researcher, Institute of Mining of Ural Branch of RAS.

Ivan L. Ozornin, head of the laboratory, Institute of Mining of Ural Branch of RAS.
20. Kornilkov S.V., Yakovlev V.L., Glebov A.V., Panzhin A.A. Rezultaty fundamentalnykh i prikladnykh nauchnykh issledovaniy IGD UrO RAN za 2012-2016 gg. [Results of basic and applied scientific research by IGD RAS 2012-2016]. Byulleten nauchnotekhnicheskoy i ekonomicheskoy informatsii, 2017, no. 1 (1405), pp. $98-103$.

21. Sashurin A.D. Forming stressed-deformed state of hierarchically unitized rock mass. Subsurface Exploitation Issues, 2015, no. 1 (4), pp. 38-44. In Rus.

22. Solovev V.A., Aptukov V.N., Vaulina I.B. Support of mining workings in saliferous rocks. Mining informational and analytical bulletin, 2017, no. 2, pp. 344-356. In Rus.

23. Balek A.E. Features of formation of stress state in support of vertical openings in hard rock masses in the post-limit stress-strain state. Mining informational and analytical bulletin, 2014, no. 11, pp. 202-212. In Rus.

24. Baklashov I.V., Kartoziya B.A. Mekhanika podzemnykh sooruzheniy $i$ konstruktsii krepey [Mechanics of underground structures and structures of supports]. Moscow, Nedra Publ., 1992. 543 p.

25. Janas P., Janas K., Koubova L., Krejsa M. Modelling of closed steel supports for underground and mining works. Key Engineering Materials, 2017, vol. 754, pp. 313-316.

Received: 8 September 2020. 